\title{
INVESTIGAÇÕES DAS POSSÍVEIS PATOLOGIAS QUE RESULTARAM NA INTERDIÇÃO DA "PONTE VELHA" NA CIDADE DE SANTA CRUZ DO CAPIBARIBE-PE, UM ESTUDO DE CASO
}

\author{
MENEZES, ISADORA. MONIQUE DE \\ Profissão: ESTUDANTE DE ENGENHARIA CIVIL \\ Instituição: CENTRO UNIVERSITÁRIO UNIFAVIP | WYDEN \\ Estado; PERNAMBUCO; País: BRASIL \\ e-mail: ISADORA123MENEZES@HOTMAIL.COM
}

\section{LAURSEN, ANDERSON}

Profissão: PROFESSOR UNIVERSÁRIO

Instituição: CENTRO UNIVERSITÁRIO UNIFAVIP | WYDEN

Estado: PERNAMBUCO; País: BRASIL

e-mail: ANDERSON.LAURSEN@UNIFAVIP.EDU.BR

\author{
SILVA, KLEYTON \\ Profissão: ESTUDANTE DE ENGENHARIA CIVIL \\ Instituição: CENTRO UNIVERSITÁRIO UNIFAVIP | WYDEN \\ Estado; PERNAMBUCO; País: BRASIL \\ e-mail: KLEYTONROBY176@GMAIL.COM
}

\author{
SILVA, EMERSON. JOSE \\ Profissão: PROFESSOR UNIVERSÁRIO \\ Instituição: CENTRO UNIVERSITÁRIO UNIFAVIP | WYDEN \\ Estado PERNAMBUCO; País: BRASIL \\ e-mail: ESILVA@UNIFAVIP.EDU.BR
}

\section{RESUMO}

Muitas são as Obras de Artes Especiais (OAEs) assim denominadas pontes e viadutos, localizadas no Brasil, que vem apresentando manifestações patológicas, devido, falhas de projetos; materiais inapropriados; erros de execução; ou por falta de manutenção. No entanto, quando ocorre uma intervenção total ou parcial de uma ponte, grandes são os transtornos para a população, que usufrui diariamente da via. Desse modo, este trabalho decorreu em uma averiguação a respeito das patologias que resultaram na interdição da "Ponte Velha", na cidade de Santa Cruz do Capibaribe-PE, através da inspeção visual. Foram realizadas visitas "in loco", com registros fotográficos e foi identificado que a ponte apresentava fissuras, corrosão das armaduras, desagregação do concreto, e um sistema de drenagem ausente. Possivelmente essas patologias foram causadas principalmente por falta de manutenção preventiva por parte dos órgãos responsáveis, em conjunto com os ataques devido à agressividade do ambiente local.

Palavra-chave: Interdição, ponte, manifestações patológicas.

\begin{abstract}
Many are the Works of Special Arts (OAEs), so-called bridges and viaducts, located in Brazil, which present pathological manifestations due to project failures; inappropriate materials; execution errors; or for lack of maintenance. However, when there is a total or partial intervention of a bridge, there are major problems for the population, which are usually daily by the road. Thus, this work was decorated on average with respect to the pathologies that resulted in the "Old Bridge" interdiction in the city of Santa Cruz de Capibaribe-PE, through visual inspection. On-site visits were carried out with photographic records and it was identified that a bridge has cracks, corrosion of arms, concrete breakdown, and an absent drainage system. Possibly these pathologies were mainly caused by the lack of preventive maintenance by the administered organs, together with attacks caused by aggressions in the local environment.
\end{abstract}

Keyword: Interdiction, bridge, pathological manifestations.

\section{INTRODUÇÃO}

De acordo com Marchetti (2008), são denominadas pontes as obras destinadas à transposição de obstáculos de uma via de comunicação qualquer. Esses obstáculos podem ser rios, braços de mar, vales profundos, outras vias, etc. Desse modo, as pontes são verdadeiros instrumentos urbanos, essenciais para o dia-a-dia da população, elas apontam os principais fluxos das vias, com intuito de diminuir caminhos, prever cruzamentos de grandes avenidas ou até mesmo, neutralizar acidentes geográficos.

Além disso, Mendes (2003) afirma que pontes são obras de artes, e devem ser projetadas levando-se em conta a viabilidade econômica e funcional, devendo oferecer resistência superior às tensões impostas, e prever métodos de conservação para garantir que a durabilidade projetada seja alcançada e suas características estéticas mantidas. 
Todavia, para que qualquer estrutura se mantenha na íntegra e assegure aos seus usuários segurança e conforto, é indispensável que ela passe por inspeções e manutenções periódicas, possibilitando, que problemas identificados na fase inicial, sejam corrigidos e solucionados. Entretanto, no Brasil é notório a escassez de programas voltados à manutenção de pontes, sendo então, um grande problema enfrentado pelo sistema rodoviário (VITÓRIO, 2006). Logo, se não há manutenção preventiva, a vida útil da obra diminuirá, facilitando o acesso das manifestações patológicas nas estruturas.

Dessa forma, patologia na construão civil é entendida como modificações estruturais e ou funcionais causadas por doença no organismo, ou seja, tudo que promove a degradação do material, das propriedades físicas ou estruturais, o qual esteja sendo solicitado. Também pode ser entendida como o baixo ou o fim do desempenho da estrutura, em relação à estabilidade, estética, serventia e, principalmente, durabilidade da mesma com relação às condições que estão submetidas (IANTAS, 2010), sendo de extrema importancia desvendar as origens que resultam as patologias.

Com isso, as origens das patologias podem surgir em diversas fases, tais como, na fase de projeto devido o descuido dos profissionais com o cumprimento das normas técnicas ou por falhas no detalhamento do projeto, ou então, na etapa de execução da obra devido o emprego de mão-de-obra desqualificada, como tambem, devido o uso de materiais de baixa qualidade, ou devido à drenagem ineficiente/ausente, pode surgir também, devido à agressividade do meio que a obra estará inserida, ou principalmente devido à falta de manutenção, durante a vida útil da obra. Logo, todos esses fatores podem resultar na aparição das principais manifestações patológicas, tais como: fissuras, trincas, rachaduras, corrosão das armaduras, desagregação do concreto, presença de umidade.

Então, fissuras, trincas e rachaduras se diferenciam devido o tamanho das aberturas, segundo a norma da NBR 9575 (2010) as fissuras têm aberturas de até $0,5 \mathrm{~mm}$, já as trincas têm aberturas maiores de $0,5 \mathrm{~mm}$ e menores de $1,0 \mathrm{~mm}$ e por fim, as rachaduras apresentam aberturas de ordem acima de 5,0 mm. No caso da corrosão das armaduras, segundo Jambor e Fósfano (2008) afirmam, é um fenômeno de degradação das armaduras do concreto armado quando são expostas ao meio corrosivo, ou seja, corresponde à deterioração do aço que acontece por uma associação de etapas químicas e eletroquímicas quando este é exposto a agentes agressivos.

Já a desagregação do concreto, nada mais é do que a perda de massa de concreto, devido ataques químicos expansivos de produtos inerentes ao concreto ou devido à baixa resistência do mesmo (MEHTA, 2008). De acordo com Piancastelli (2015), a desagregação inicia-se geralmente com a alteração da coloração do concreto, em seguida surgem fissuras cruzadas em todas as direções, que aumenta rapidamente de abertura devido à expansão da pasta de cimento.

Segundo Laner (2001), a presença de umidade no pavimento, é um fator que também influencia na degradação do concreto e das armações. Por esse motivo, ela deve ser evitada para que, de fato, não se deixe água acumular em pontos críticos como, por exemplo, encontros de apoio de vigas, nos caixões, nos encontros com tabuleiros, na pista de rolamento, nos aparelhos de apoio, entre outros. No entanto, "As ações que a água pode causar são devastadoras para uma ponte, tanto para o tráfego sobre ela quanto para a funcionalidade estrutural” (VASCONCELOS, 2018).

Contudo, a "Ponte Velha" popularmente conhecida, na cidade de Santa Cruz do Capibaribe-PE, que tem uma grande importância urbano-social e econômica para o município, desencadeou sérios problemas estruturais, devido à presença de manifestações patológicas, levando-a então, a uma interdição de veículos por tempo indeterminado, ordenada pela Nota técnica No 034/2019 - CEPDC/CAMIL.

Assim, a escolha do tema se justifica pela necessidade de conhecer as possíveis causas das manifestaões patologicas que sucedeu na interdição da Ponte Velha, que resultou em impactos negativos, para a cidade mencionada. Por esta razão, ao longo deste trabalho serão apresentadas soluções de reparo para esta ponte, para que a mesma volte a fornecer segurança as pessoas e veículos que antes trafegavam diariamente, sobre ela.

Portanto, o presente trabalho tem como objetivo geral, abordar as principais causas que acometeram para a interdição de veículos, de uma ponte, em Santa Cruz do Capibaribe-PE, por meio de inspeções visuais e para que seja possível atingilo, foi necessário enumerar alguns objetivos específicos como: apontar as principais manifestações patológicas que ocorreram na "Ponte Velha"; Relatar a importância que a mesma tem, para a economia e mobilidade urbana na cidade de Santa Cruz do Capibaribe e apresentar soluções de reparo, que aumente a vida útil da ponte em estudo. 


\section{Metodologia}

A metodologia adotada neste trabalho foi um estudo de caso, referente às prováveis manifestações patológicas que podem ocorrer em uma Obra de Arte Especial (OAE) e suas prováveis soluções de reparo, que possam aumentar a vida útil do objeto em estudo. As considerações realizadas foram fundamentadas em inspeções visuais, não sendo usado nenhum tipo de aparelhagem ou realizado qualquer tipo de ensaio, tornando assim, um trabalho teórico-prático. Entretanto, as fundações não foram inspecionadas devido às mesmas, se encontrarem enterradas. Contudo, na Figura 1 será ilustrado o fluxograma adotado na metodologia deste artigo.

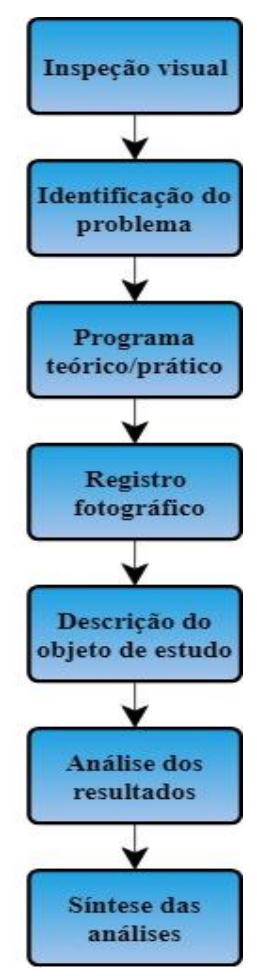

Figura 1 - Fluxograma da metodologia (Autores, 2019)

O fluxograma adotado na metodologia deste trabalho iniciou com inspeção visual, que teve como objetivo analisar os problemas que a interdição da Ponte Velha trouxe para a população, com isso, foi caracterizado a natureza do artigo como um programa teórico/prático e então, foi realizado o levantamento de dados com o auxílio dos registros fotográficos, para a obtenção de informações referentes às patologias que resultaram nos impactos negativos para a população. No entanto, foi descrito o objeto de estudo do trabalho que é a Ponte velha e por fim, foi feito uma análise e discussão dos resultados encontrados pelos os autores.

\subsection{Objeto de estudo}

A ponte em estudo, designada como "Ponte Velha" pelos moradores da cidade de Santa Cruz do Capibaribe-PE, teve sua construção concluída acerca do ano 1950 (segundo informações da Defesa Civil, (2019)).

Ela se estende sobre o Riacho Tapera, afluente do Rio Capibaribe, assim representada nas Figura 2 e Figura 3. 


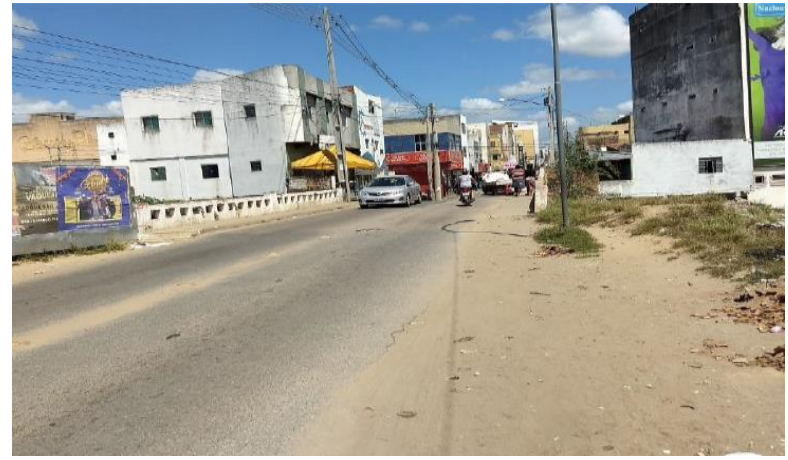

Figura 2 - Vista frontal da Ponte, antes da interdição (Nota técnica No 034/2019 CEPDC/CAMIL, 2019).

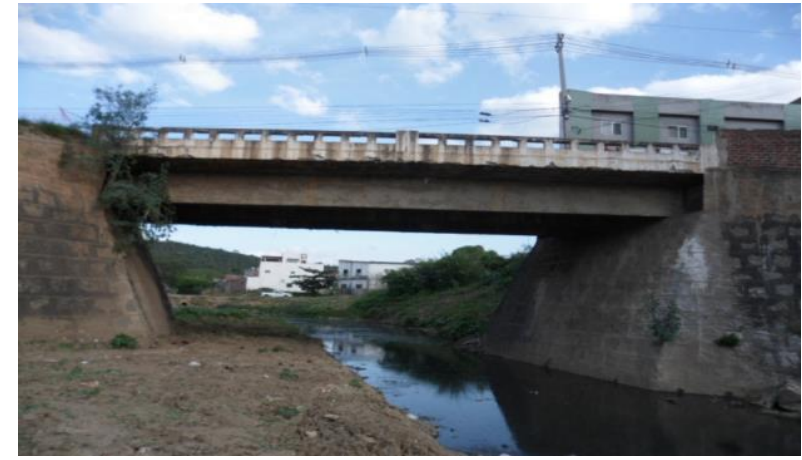

Figura 3 - Vista lateral da Ponte (Autores, 2019)

Além disso, é uma obra de arte pertencente ao governo do Estado de Pernambuco, que conecta as Av. Prefeito Teófanes Ferraz Torres Filho e a Av. João Francisco Aragão, que é o principal acesso da PE-160 ao Centro da cidade, com coordenadas $7^{\circ} 57^{\prime} 26.6^{\prime \prime S ~ e ~} 36^{\circ} 11^{\prime} 58.7^{\prime \prime W}$. Melhor identificada na Figura 4.

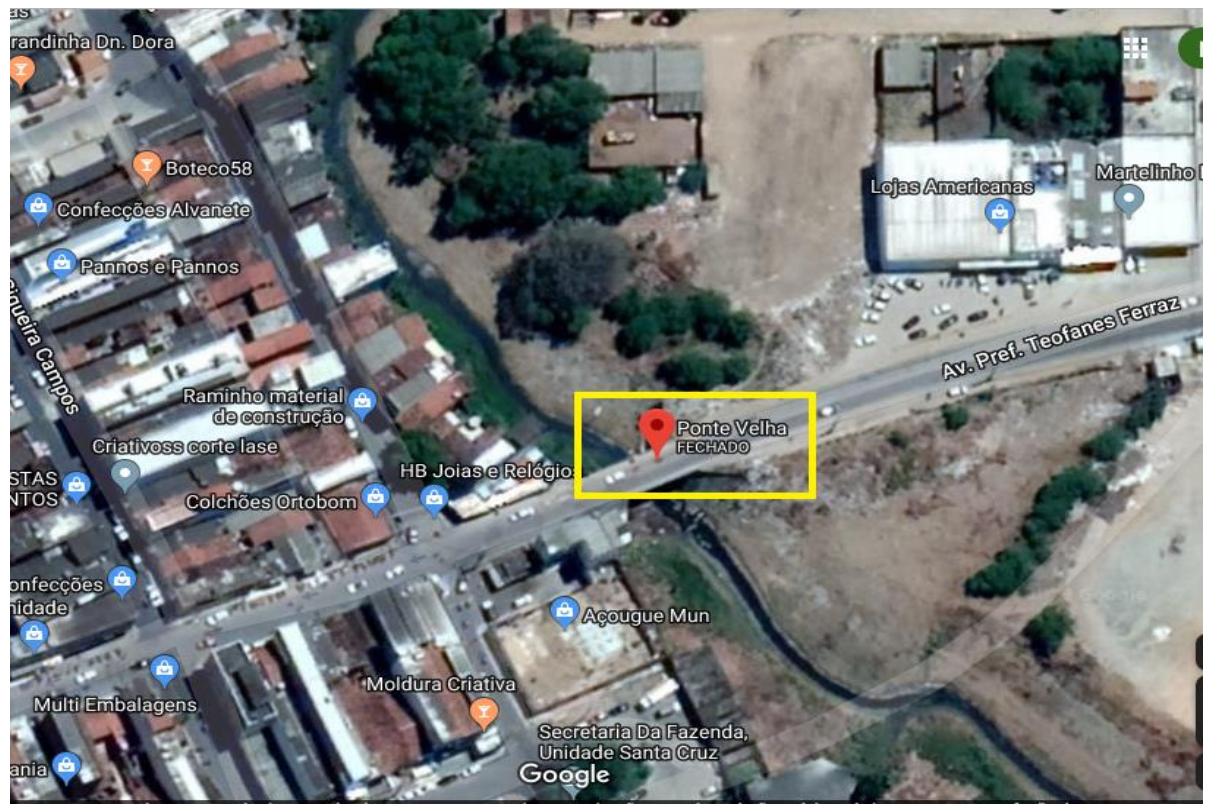

Figura 4 - Localização da ponte via satélite (Google Maps, 2019).

Desse modo, a ponte contém uma extensão de $8 \mathrm{~m}$ de largura por $18 \mathrm{~m}$ de comprimento, a pista de rolamento é constituída por asfalto, e tem dois espaços voltados para o passeio de pedestres nas laterais, que são limitados e contidos por guardas-corpos de concreto armado, sua estrutura é composta por uma laje de concreto armado, apoiada sobre três vigas longarinas travadas lateralmente entre si, por cinco vigas transversinas.

\section{RESULTADOS E DISCUSSÕES}

\subsection{Interdição da ponte}

Desde que essa obra foi concluída em torno da década de 1950, não se teve evidências de manutenção sobre ela, ocasionando desgastes de seus elementos. Por isso, foi necessário interditar o acesso de veículos sobre a ponte no dia 15 de junho de 2019, por tempo indeterminado, após um laudo técnico emitido sobre a situação precária da ponte, solicitado pela Prefeitura Municipal, representada pela Secretaria de Desenvolvimento Urbano junto com a Coordenação de Defesa Civil Municipal. 
Então, a ponte foi interditada com tapumes no seu entorno, e tonéis para a sustentação dos mesmos, e foi determinado que ela fosse escorada, a fim de garantir a estabilidade de toda estrutura, contudo, esse escoramento não foi realizado. Além disso, foi permitido apenas à passagem de pedestres pelo lado direito da ponte, como representado na Figura 5 e Figura 6.

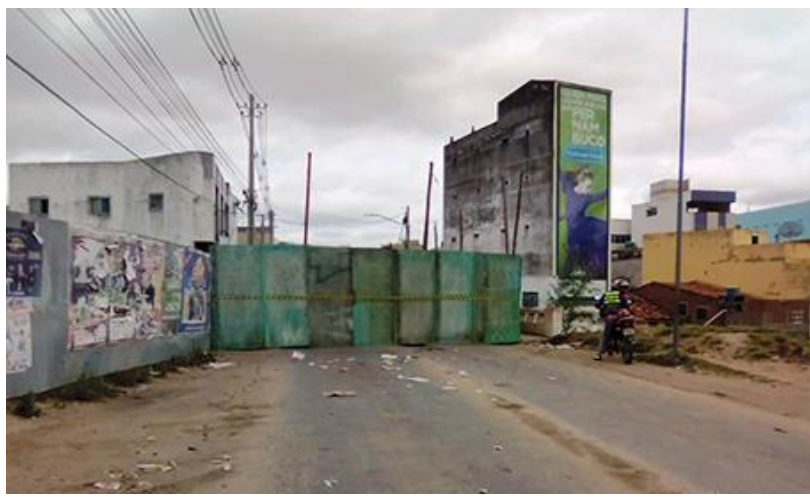

Figura 5 - Vista frontal da Ponte interditada (Lima et al., 2019)

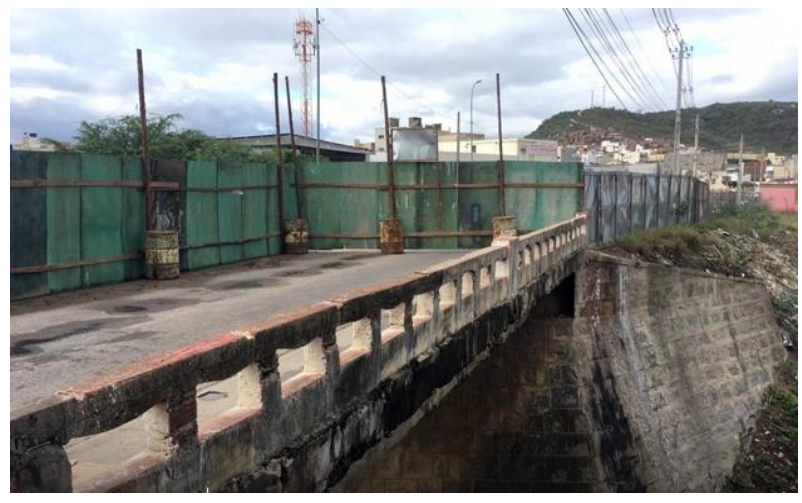

Figura 6 - Vista interna da Ponte interditada (Muniz, 2019)

Porém, devido à precariedade física e o elevado grau de deterioração da ponte, a interdição da mesma deveria ter sido total, proibindo além da passagem dos veículos, a passagem dos pedestres, visto que, de acordo com a NBR 6118 (2014) o estado limite de serviço da mesma, já não atende as condições de projeto, chegando cada vez mais próximo, ao estado limite último, ou seja, ao colapso.

Dessa forma, tanto a mobilidade urbana, quanto a economia da cidade foram afetadas, após essa interdição, pois a Ponte Velha é o principal acesso ao centro da cidade. Com isso, a Câmara de Dirigentes Lojistas (CDL, 2019) da cidade, apontou uma redução de $60 \%$ nas vendas dos comerciantes santa-cruzense, devido aos transtornos da interdição dessa ponte, que afetou diretamente a mobilidade urbana, fazendo diminuir significativamente a presença de veículos nos estabelecimentos comerciais, pois os mesmos teriam que percorrer longos $\mathrm{km}$, sem saber ao certo, quais ruas poderiam utilizar para chegar e para sair do local almejado, devido à existência de mão única e mão dupla.

Pensando-se nesses transtornos, foram realizadas as inspeções visuais, com o intuito de apontar as principais patologias que resultaram na interdição da Ponte Velha.

\subsection{Principais patologias identificadas}

\subsubsection{Fissuras, trincas e rachaduras}

De acordo com as inspeções visuais realizada em dois dias, foram identificadas fissuras, trincas e rachaduras no muro de arrimo da ponte, ilustrada nas Figuras, 7, 8 e 9, causadas devido às condições externas impostas pelo ambiente, como também, devido às sobrecargas ocasionadas pelo fluxo de veículos sobre o pavimento flexível, conforme foi citado por Felix et al. (2017). 


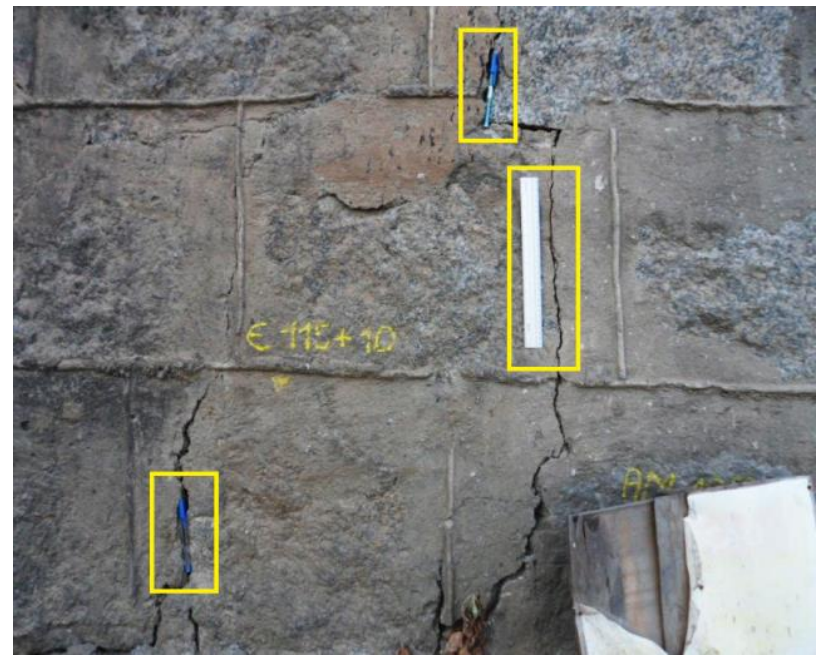

Figura 7 - Trincas e fissuras ao longo do talude (Autores, 2019)

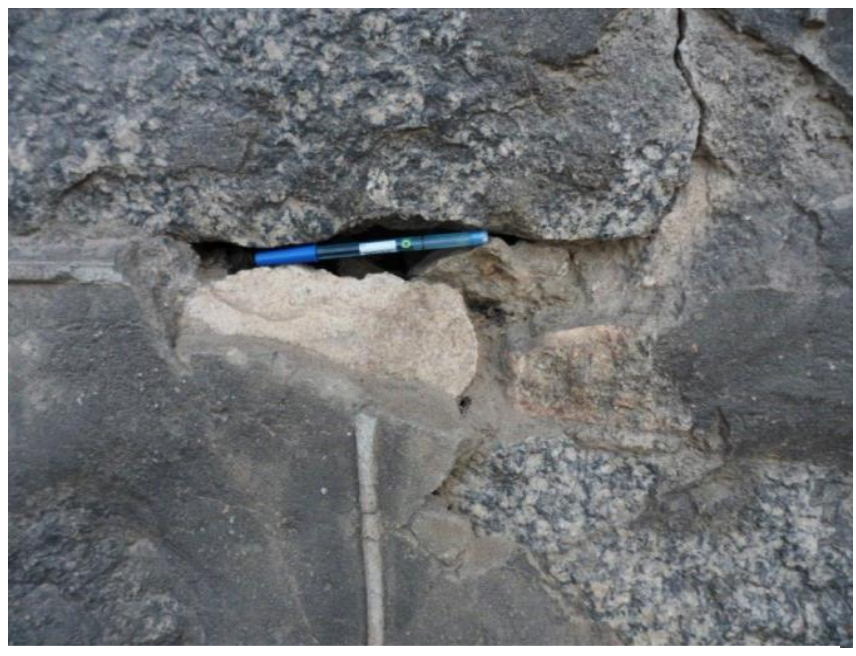

Figura 8 - Rachadura no talude (Autores, 2019)

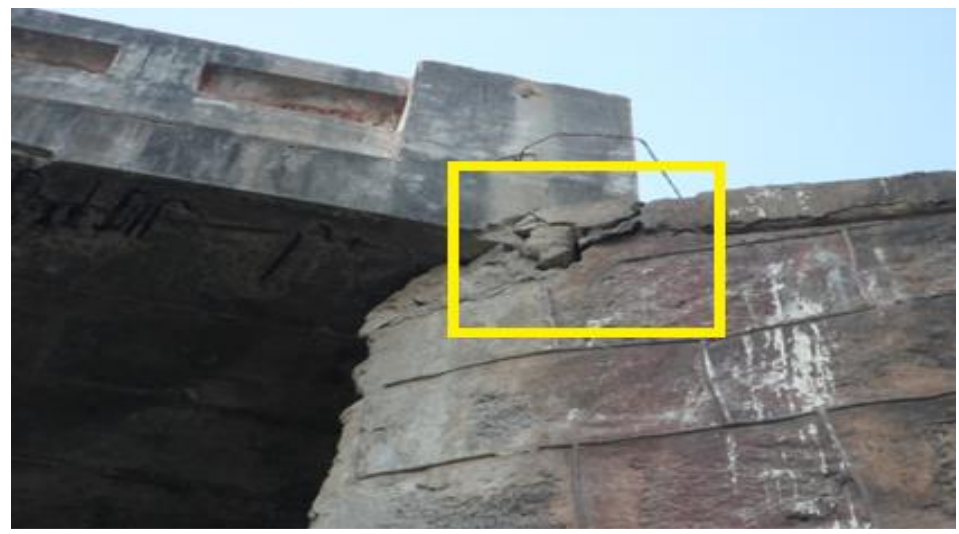

Figura 9 - Trincas no encontro entre a ponte e o talude (Autores, 2019)

Também foi possível observar fissuras nas vigas longarinas e transversinas Figuras 10 e 11, sendo elas, o principal acesso para o oxigênio $\left(\mathrm{O}_{2}\right)$, dióxido de carbono $\left(\mathrm{CO}_{2}\right)$, íons sulfeto $\left(\mathrm{S}^{2}-\right)$, umidade $\left(\mathrm{H}_{2} \mathrm{O}\right)$, adentrar nas armaduras, também verificado por Silva et al. (2019).

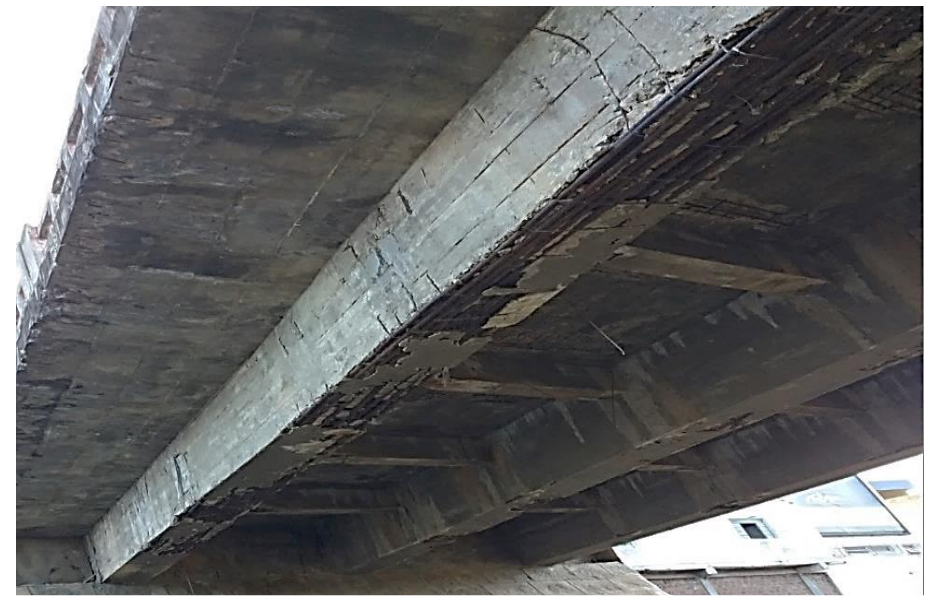

Figura 10 - Fissuras paralelas ao aço, na viga longarina (Autores, 2019)

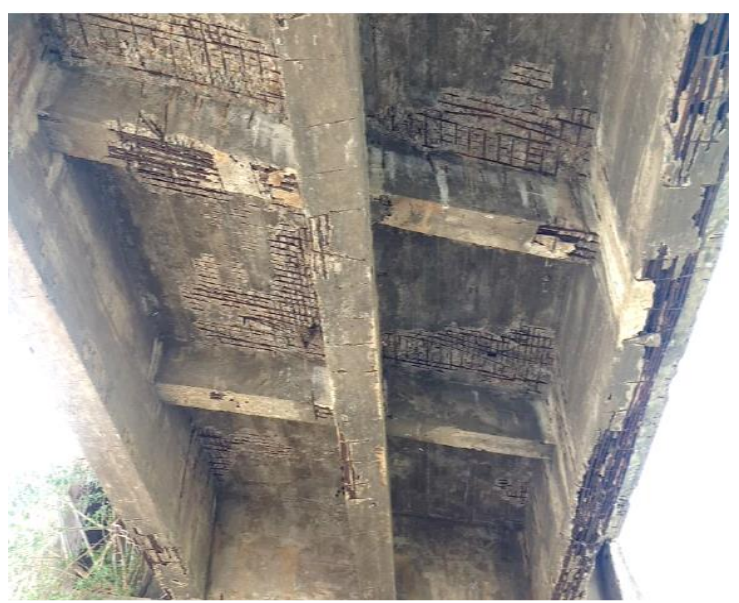

Figura 11 - Fissuras paralelas ao aço, nas vigas transversinas (Autores, 2019) 
Em virtude dos ataques químicos, foi visualizado que o aço do concreto armado ao ser atingido, mudou consequentemente as características iniciais de projeto, e aumentou de volume, resultando então, em tensões internas no concreto e no surgimento de fissuras paralelas, também verificado por Nascimento et al. (2018).

\subsubsection{Corrosão das armaduras}

Compreendido que o surgimento fissuras paralelas ao aço do concreto é indicativo de corrosão das armaduras, foi verificado que praticamente toda a estrutura da ponte, está altamente corroída e em vários trechos da laje do tabuleiro, pode-se visualizar armadura rompida, assim identificada nas Figuras 12 e 13.
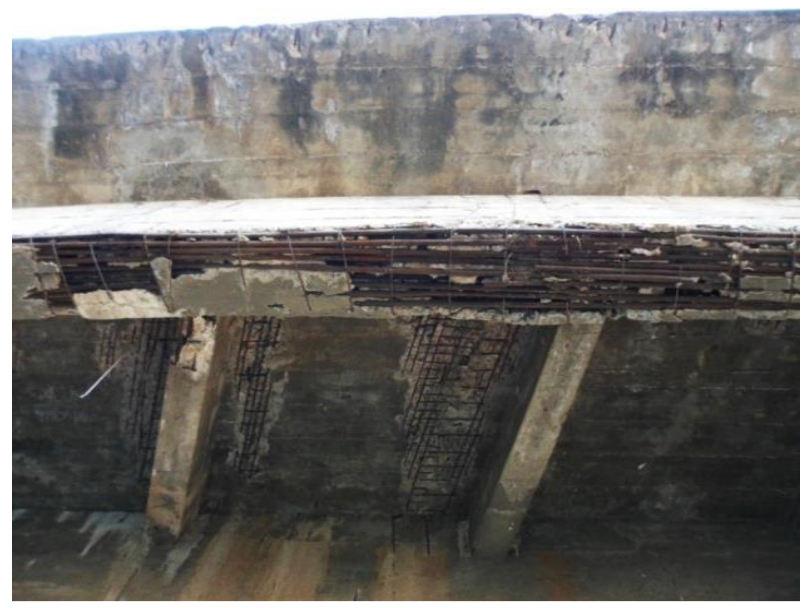

Figura 12 - Corrosão de armadura em uma das vigas longarinas (Autores, 2019)

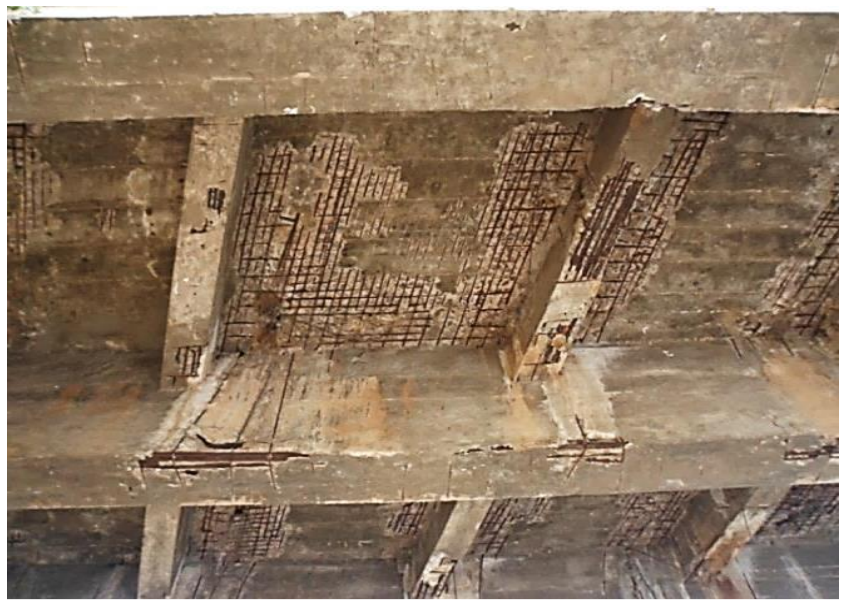

Figura 13 - Laje do tabuleiro com presença de corrosão de armadura, assim como, com armadura rompida (Autores, 2019)

Com isso, o processo corrosivo acarretará na destruição do aço, que origina problemas tanto na utilização, quanto na estética e segurança das estruturas, relacionado à perda da capacidade, de resistir aos esforços solicitantes, problema patológico também observado por Quadros e Borgens (2019).

Contudo, tendo em vista a elevada deterioração e exposição do aço da ponte analisada, a corrosão das armaduras se mostrou uma das patologias mais frequentes na estrutura, e consequentemente uma das mais perigosas, visto que, a principal função do aço é oferecer resistência à tração ao concreto, no entanto, pode-se afirmar que o aço já não atende as condições iniciais de projeto, e poderá levar a estrutura à ruína.

\subsubsection{Umidade}

Ao visitar a ponte em estudo foram detectadas manchas de umidade na ponte e no talude, assim como, foi observada a presença de vegetação nos encontros, ilutradas nas Figuras 14 e 15, do mesmo modo que Ancajema; Botoni e Ytza, (2019) também verificaram.

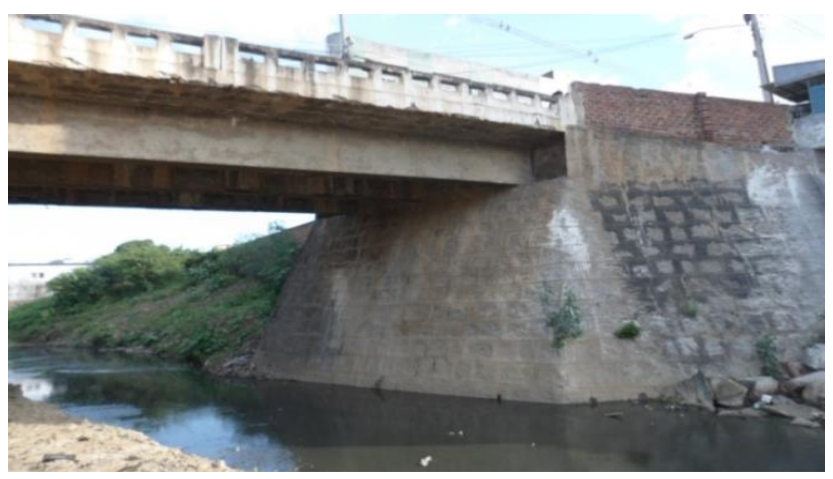

Figura 14 - Mancha de umidade (Autores, 2019)

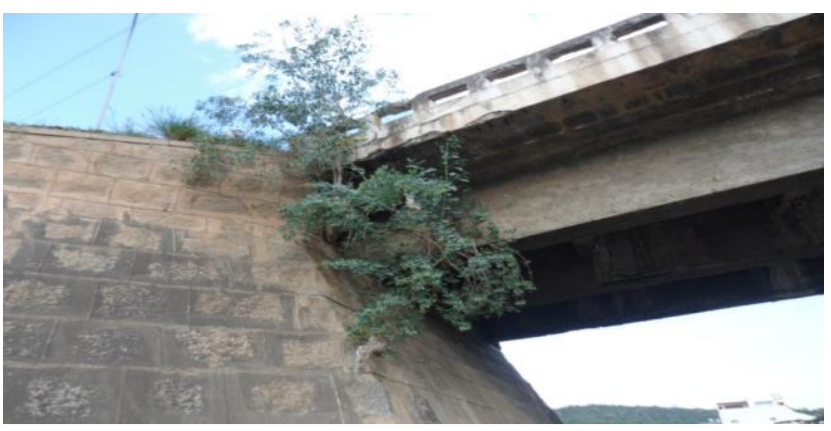

Figura 15 - Presença de vegetação nos encontros (Autores, 2019) 
Dessa forma, foi possível detectar que o sistema de drenagem desta ponte é ausente/ineficiente, pois durante a inspeção, notou-se a falta drenos, para realização do sistema de drenagem da água pluvial, desta obra de arte especial, sendo então, a infiltração de água, uma das grandes causas para o nascimento das fissuras, desagregação do concreto, corrosão de armadura, eflorescência, conforme verificado por (Simão; Oliveira e Silva, 2019).

É válido ressaltar que a umidade não é apenas um agente resultante de patologias, pois a mesma, também vai agir como um intermédio necessário, para que outras patologias ocorram nas construções civis, tendo como consequência, a diminuição do desempenho e da vida útil da estrutura. Com isso, o conhecimento e a identificação das causas da presença de umidade, são aspectos importantes na solução e precaução de problemas ainda maiores.

\subsubsection{Desagregação do concreto}

Tendo em vista uma possível frente de carbonatação no concreto, as Figuras 16, 17 e 18 representam a desagregação do concreto ou perda de revestimento, que foi notada nos guardas-corpos, na laje, assim como, nas vigas longarinas e transversinas, também observado por Rocha e Pereira (2019).

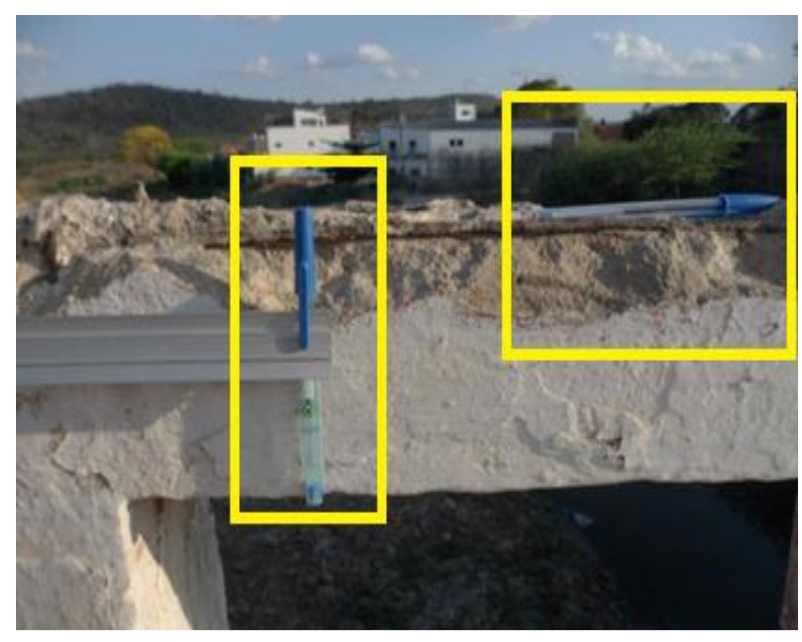

Figura 16 - Perda de massa no guarda corpo (Autores, 2019)

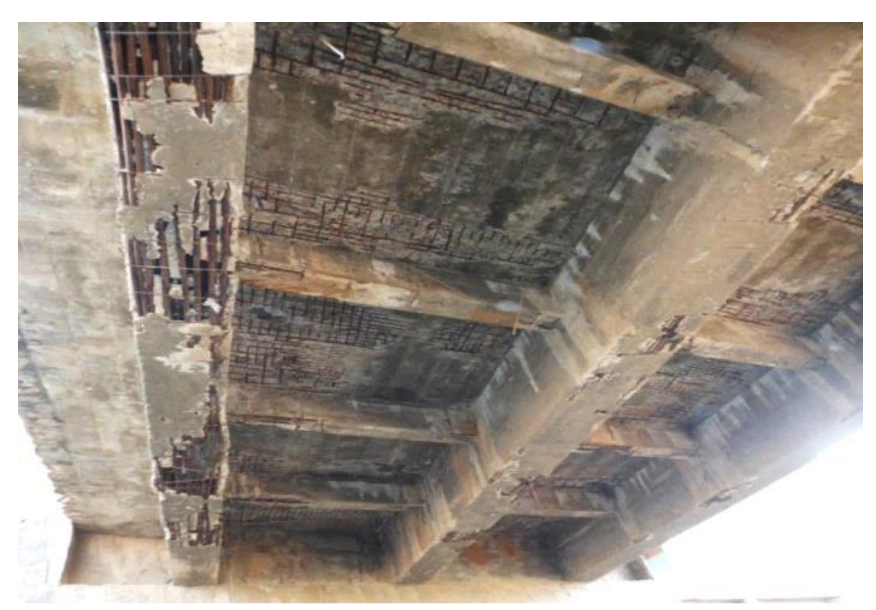

Figura 17 - Viga e laje com concreto desagregado

(Autores, 2019)

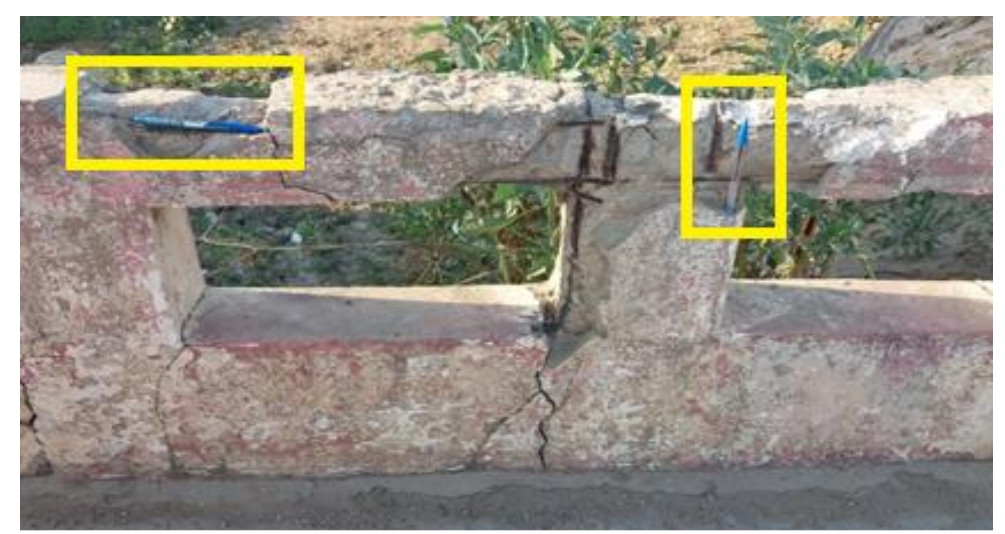

Figura 18 - Guarda corpo do lado esquerdo já bem

deteriorado (Autores, 2019)

Então, a perca de seção dos elementos analisados resultante da desagregação do concreto, foi causado devido à agressividade do ambiente, presença de umidade, armaduras oxidadas e corroídas, dos cobrimentos e espaçamentos mínimos não respeitados para vigas e laje, ou até mesmo, devido à aplicação de material de baixa qualidade. 


\subsection{Consequências após a interdição da ponte}

Com o intuito de diminuir os impactos causados a partir da interdição da Ponte Velha, a prefeitura municipal de Santa Cruz do Capibaribe, abriu uma passagem molhada ao lado da ponte, Figura 19, para que o fluxo de veículos que diariamente iria trafegar por ela, fosse transferido para a passagem molhada.

Porém, por tratar de uma obra de grande importância, para economia e mobilidade da cidade, pessoas não identificadas retiraram todo tapume do entorno da ponte, assim como, as placas de identificação da interdição, com o objetivo de permitir o tráfego sobre a mesma novamente, assim identificada na Figura 20.

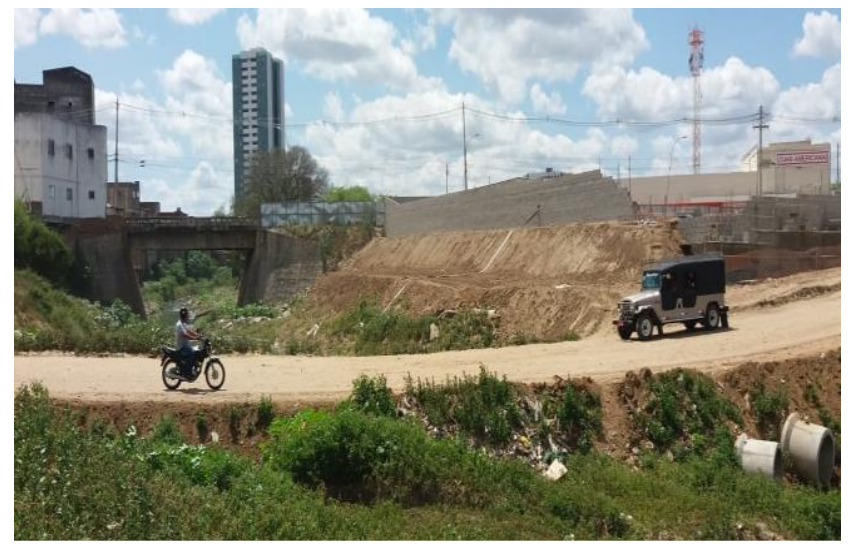

Figura 19 - Abertura de uma passagem molhada (Autores, 2019)

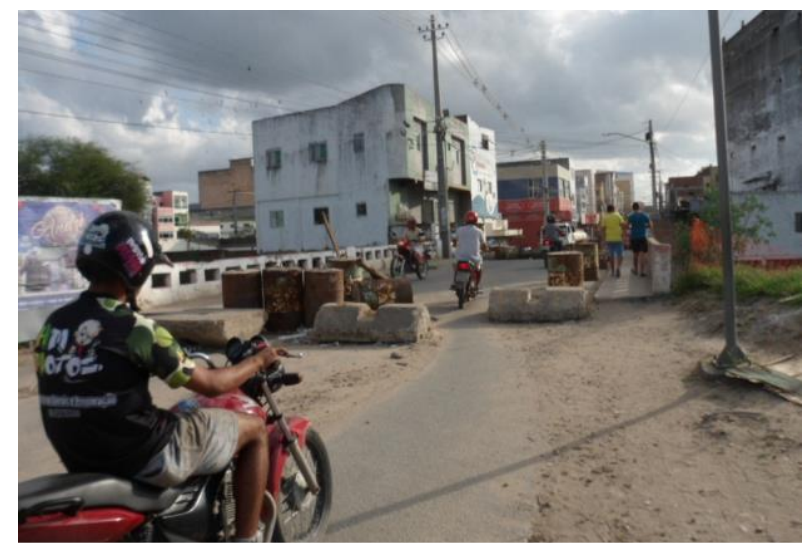

Figura 20 - Tráfego de moto sobre a ponte interditada (Autores, 2019)

Desse modo, esse ato de vandalismo pode acarretar no colapso total da estrutura, a qualquer momento, devido as solicitações diárias que o tráfego de motos, bicicletas e pedestres, estão fazendo nas estruturas precárias que compõem a Ponte Velha, pondo em risco as vidas que habitam nas casas vizinhas, a mobilidade urbana da cidade e do futuro do comércio.

\subsection{Técnicas de recuperação}

Cada tipo de patologia pode apresentar diversos procedimentos para a sua correção, que exigem desde materiais e equipamentos até metodologias de execução diferenciadas. A metodologia de reparo mais adequada pode ser definida levando em consideração fatores técnicos e econômicos (FERREIRA, 2016).

Tendo em vista a precária situação estrutural da Ponte Velha, é preciso que seja realizado um projeto estrutural com base na NBR 6118:2014 por profissionais qualificados da área, de modo que, se evite projetos mal elaborados e mal detalhados, repassado para os profissionais especializados, que serão encarregados de executar essa recuperação.

Desse modo, com todos os parâmetros de projeto definido, e conhecendo todas as causas que resultaram no desgaste da OAE, deve ser iniciada a recuperação com o escoramento da superestrutura desta ponte, ou seja, das vigas e da laje de tabuleiro.

No entanto, para a correta recuperação das fissuras, o primeiro passo deve ser analisada a causa, para em seguida poder recupera-las, então, é necessário que a região seja limpada para poder averiguar se a fissura é passiva ou ativa, para isso, é preciso passar uma pasta de gesso na fissura e esperar um tempo mínimo de 24 horas, se a pasta de gesso trincar, significa dizer que é uma fissura ativa e deve ser recuperada com injeções de materiais flexíveis, como por exemplo, "selante plástico", porém, se o gesso não trincar, significa dizer que a fissura é passiva e deve ser tratada com injeções de materiais rígidos como o "resinas epóxi".

No caso do tratamento da corrosão das armaduras, a princípio será preciso demarcar a área a ser recuperada, em seguida, será feito a extração do material danificado para realizar a limpeza, que poderá ser manual ou mecanizada, com isso, será constituída a camada de aderência do aço para receber a pintura, ou seja, o revestimento, por fim, será restaurado e realizado a proteção da supecifície do concreto. 
Para a recuperação do concreto desagregado, também será delimitado a área afetada, por conseguinte, será removido o concreto deteriorado para a limpeza do substrato, então, será realizado o apicoamento da superfície, e por fim, vai ocorrer à reconstituição da do concreto que ocorrerá com a utilização de argamassa de cimento Portland enriquecida por microsílica, acrílico, látex ou epóxi, ou então, com argamassa polimérica/grout ou microconcreto.

Além disso, como não foram detectados sistemas de drenagem, é de extrema importância que ele seja implantado na Ponte Velha, de forma recomendada por Vasconcelos (2018), ou seja, deve possuir condições que, possibilite declividade única caso seja uma obra de arte curta, e sempre que possível, executar declividade de pelo menos $2 \%$, assim, ela deve possuir elementos de captação de água pluvial em bom estado, e também deve possuir drenos que evitem acúmulo de água na parte interna da estrutura com distanciamento adequado por norma, para que a deterioração da estrutura por acúmulo de água seja evitada. Logo, é preciso que seja garantido a extinção do empoçamento d'água sobre o pavimento e sobre os elementos estruturais, pois um sistema de drenagem ineficiente/ausente é porta para grande parte das patologias.

Por fim, devido o grau de degradação dos guarda corpos de concreto armado, não se indica fazer a recuperação dele, mas sim, a substituição por outro, proporcionando mais segurança aos usuários do ambiente.

Os avanços tecnológicos e o conhecimento sobre o comportamento dos materiais, suas propriedades e características, são de grande importância no ramo da construção civil, para corroborar ou modificar os parâmetros presentes nas normas reguladoras, com o objetivo de construir e projetar estruturas que apresentem uma vida útil maior associada a uma maior economia no processo de execução (FERREIRA, 2016).

\section{CONSIDERAÇÕES FINAIS}

Diante de tudo que foi exposto, foi possível detectar, que os principais fatores para o elevado grau de deterioração da Ponte Velha em Santa Cruz do Capibaribe-PE, foram causados pela falta de manutenção dos seus elementos, como também, devido à agressividade do ambiente e pelo sistema de drenagem ausente.

Dessa forma, os profissionais da construção civil necessitam estar sempre atentos e prevendo em projetos, à agressividade do meio que essas OAE estão inseridas, pois as estruturas de concreto armado estão sempre susceptíveis, a ataques físico-químicos.

Além de medidas apropriadas de manutenção, é necessário que se tenha uma implementação mais rigorosa das exigências das normas vigentes nas etapas de projeto, execução e de uso, de modo a evitar a origem das patologias.

Diante disso, as patologias mais incidentes nesta ponte foram: fissuras, corrosão das armaduras, desagregação do concreto, ausência/ineficiência do sistema de drenagem, patologias essas quem afetam as condições de serviço, bom funcionamento e as condições de segurança da estrutura.

Portanto, tais diagnósticos só podem ser apresentados, após uma inspeção detalhada referente às causas e suas origens, visto que, erros no diagnóstico, acarretará na não resolução do dano, além de prejuízos financeiros, assim como, no desperdício de tempo para solucionar o problema inicial.

\section{REFERÊNCIAS}

ANCAJEMA, A. L. C.; BOTONI, B. V.; YTZA, M. F. Q. Estudo de caso de uma vistoria em um viaduto. Ibracon: Anais do $61^{\circ}$ Congresso Brasileiro do concreto armado CBC2019, Fortaleza, Outubro 2019. ISSN $2175-8182$.

ASSOCIAÇÃO BRASILEIRA DE NORMAS TÉCNICAS. NBR 9575. Impermeabilização - Seleção e projeto. Rio de Janeiro. 2010.

ASSOCIAÇÃO BRASILEIRA DE NORMAS TÉCNICAS. NBR 6118:2014. Projeto de estruturas de concreto Procedimento. Rio de Janeiro. 2014.

FERREIRA, I. K. A. Patologia em estruturas de concreto armado: Estudo realizado nas edificações do centro de tecnologia do campos I da universidade Federal da Paraíba. Trabalho de Conclusão de Curso: Graduação em Engenharia Civil da Universidade Federal da Paraíba-UFPB. João Pessoa. 2016. 
IANTAS, L. C. Estudo de caso: Análise de patologias. (Monografia em engenharia civil) - Universidade Federal do Paraná. Curitiba. 2010.

JAMBO, H. C M.; FÓFANO, S. Corrosão - Fundamentos, monitoração e controle. 1. ed. Rio de Janeiro: Ciência Moderna, 2008.

LANER, F. J. Manifestações Patológicas nos Viadutos, Pontes e Passarelas do Município de Porto Alegre. Dissertação (Pós-Graduação) - Faculdade de Engenharia Civil, Universidade Federal do Rio Grande do Sul. Porto Alegre. 2001.

MARCHETTI, O. Pontes de concreto armado. São Paulo: Blucher, 2008.

MEHTA, P. K.; MONTEIRO, P. J. M. Concreto - microestrutura, propriedades e materiais. São Paulo: IBRACON, 2008.

MENDES, L. C. Pontes. 2a . ed. Revista e ampliada. Niterói: Eduff, 2003.

NASCIMENTO, C. D. C. et al. Patologias em ponte de concreto armado: causas e reforços na ponte da Corvina em Salinópolis-PA. Ibracon: Anais do $6^{\circ}$ Congresso Brasileiro do concreto armado CBC2018, Foz do Iguaçu, Setembro 2018. ISSN 2175-8182.

NOTA TÉCNICA No 034/2019 - CEPDC/CAMIL. Vistoria Técnica na Ponte Velha - Santa Cruz do Capibaribe PE. Recife. 2019. Disponivel em: < http://www.blogdoneylima.com.br/wp-content/uploads/2019/07/OFICIO.pdf〉. Acesso em: 03 jul 2019.

PIANCASTELLI, É. M. Sintomas e causas das enfermidades, 2015. Disponivel em: <https://pt.slideshare.net/cepdn/patologias-45673236>. Acesso em: 05 ago 2019.

QUADROS, H. S.; BORGES, T. R. Vistoria e projeto de alteraão do uso de ontes e viadutos. Ibacon: Anais do 59 ${ }^{\circ}$ Congresso Brasileiro do concreto CBC2017, Bento Gonçalves, Outubro-Novembro 2017. ISSN 2175-8182.

ROCHA, D. M. A.; PEREIRA, F. S. D. C. Manutenção e procedimento de gestão para a ponte Newton Navarro. Ibracon: Anais do $6^{\circ}$ Congresso Brasileiro do concreto armado CBC2019, Fortaleza, Outubro 2019. ISSN 21758182 .

SILVA, A. N. B. W. et al. Estudo das patologias em concreto armado na ponte de Porto Nacional - TO. Ibracon: Anais do $61^{\circ}$ Congresso Brasileiro do concreto armado CBC2019, Fortaleza, Outubro 2019. ISSN 2175-8182.

SIMÃO, G. L. D. O.; OLIVEIRA, R. C.; SILVA, C. G. M. Resultados de inspeções em pontes de concreto armado. Ibracon: Anais do $61^{\circ}$ Congresso Brasileiro do concreto armado CBC2019, Fortaleza, Outubro 2019. ISSN 21758182 .

VASCONCELOS, F. D. O. Analise das manifestaões patológicas em pontes de concreto armado - Estudo de caso. Trabalho de conclusão de curso (Engenharia Civil) - Universidade Federal de Alagoas Campus do Sertão. Delmiro Gouveia. 2018. 